\title{
Preface of the special issue "Thin Films Advances" dedicated to the 75th birthday of Professor Joe Greene
}

Ivan Petrov, Lars Hultman, Michael Stueber, Li-Chyong Chen and Patrick Desjardins

The self-archived postprint version of this journal article is available at Linköping University Institutional Repository (DiVA):

http://urn.kb.se/resolve?urn=urn:nbn:se:liu:diva-160974

N.B.: When citing this work, cite the original publication.

Petrov, I., Hultman, L., Stueber, M., Chen, L., Desjardins, P., (2019), Preface of the special issue "Thin Films Advances" dedicated to the 75th birthday of Professor Joe Greene, Thin Solid Films, 688,

137494. https://doi.org/10.1016/j.tsf.2019.137494

Original publication available at:

https://doi.org/10.1016/j.tsf.2019.137494

Copyright: Elsevier

http://www.elsevier.com/

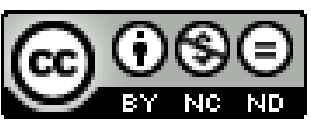




\section{Preface of the Special Issue "Thin Films Advances"}

\section{Dedicated to the $\mathbf{7 5}^{\text {th }}$ birthday of Professor Joe Greene}

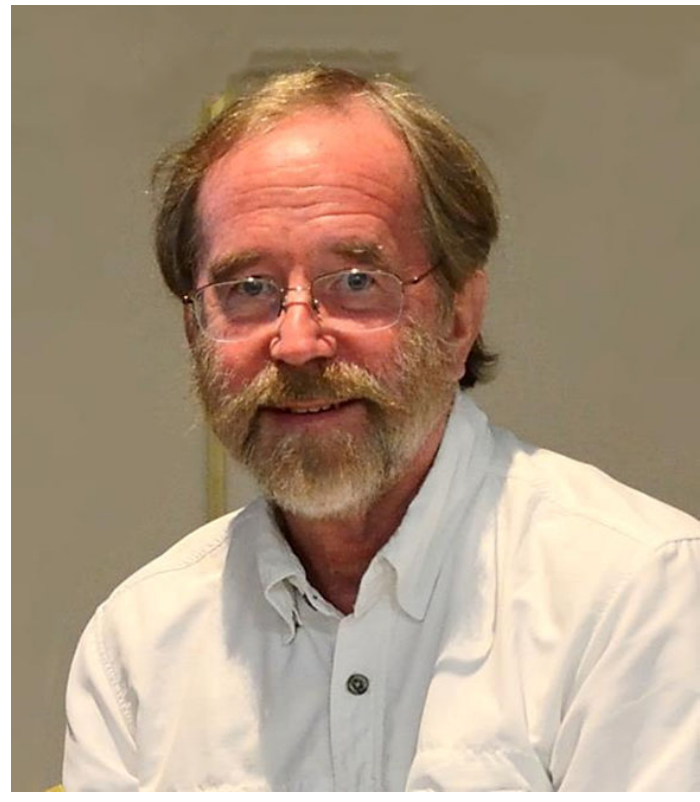

Professor Joe Greene

This Special Issue of Thin Solid Films is compiled to recognize, appreciate, and honor the exceptional contributions of Professor Joe Greene as a scientist, teacher, and leader of the international community on the occasion of his $75^{\text {th }}$ birthday. It contains 55 original and review articles by scientists from around the globe who wish to acknowledge Joe's positive influence on the field of thin film physics as well as on their careers and research. Joe's scientific output is characterized by overwhelming numbers: over 625 research and review articles, 29 book chapters, four co-edited books, 525 invited talks and 140 plenary lectures. These span over five decades containing numerous seminal contributions in the general areas of thin film physics, surface science, and advanced surface engineering.

As a graduate student at the University of Southern California, Joe started with synthesizing by liquid-phase epitaxy GaAs (001) films which were of very high quality as demonstrated by Hall and photoluminescence measurements. At that time there were no techniques sensitive enough to determine the remaining residual impurities. This led Joe to develop glowdischarge optical spectroscopy (GDOS), the optical analog of modern secondary ion mass spectrometry, with initial detection limit $=3 \times 10^{16}$ atoms $/ \mathrm{cm}^{3}, 680 \mathrm{ppb}$. Since then, many others worldwide, have employed GDOS to quantitatively measure dopant diffusion and ionimplantation profiles in III-V, SiGe, and solar cell absorber layers.

At the University of Illinois at Urbana-Champaign, in addition to developing further GDOS, Joe continued epitaxial semiconductor film growth, but switched to SiGe via Ultra-high Vacuum Chemical Vapor Deposition (UHV-CVD), metastable (III-V)1-x $\left(\mathrm{IV}_{2}\right)_{\mathrm{x}}$ alloys (the 
"Greene" alloys) by UHV sputter deposition, and GaN by reactive-ion Molecular Beam Epitaxy (MBE). SiGe CVD was carried out in UHV in order to employ in-situ surface-science tools (including Reflection High Energy Electron Diffraction, Temperature Programmed Desorption, Auger Electron Spectroscopy, X-ray Photoelectron Spectroscopy, Ultraviolet Photoelectron Spectroscopy, High Resolution Electron Energy Loss Spectroscopy, and Variable Temperature Scanning Tunneling Microscopy) to investigate atomic-scale growth kinetics. The Greene research group developed models, with no fitting parameters, to accurately predict $\mathrm{Si}, \mathrm{Si}_{1-\mathrm{x}} \mathrm{Ge}_{\mathrm{x}}, \mathrm{Si}_{1-\mathrm{x}} \mathrm{C}_{\mathrm{x}}$, and $\mathrm{Ge}_{1-\mathrm{x}} \mathrm{Sn}_{\mathrm{x}}$ film growth rates, compositions, and doping profiles as a function of precursor partial pressures and deposition temperatures. The Greene alloys (e.g.: $\left.(\mathrm{GaAs})_{1-\mathrm{x}}\left(\mathrm{Ge}_{2}\right)_{\mathrm{x}}\right)$ were grown across pseudobinary phase diagrams and exhibited good thermal stability. They have interesting electronic transport, band structure, and phonon properties and are currently used in tunable photodetector and piezoelectric devices. The first high-resistivity single-crystal GaN films, both wurtzite and zincblende, were grown by MBE using evaporated $\mathrm{Ga}$ and $35 \mathrm{eV} \mathrm{N}_{2}{ }^{+}$ions. The layers, which had the highest electron mobilities yet reported, were used to determine hexagonal and cubic $\mathrm{GaN}$ band structures.

Following an invitation to present a Swedish Academy of Science Lecture in the 1980s, colleagues from Linköping University ignited Joe's interest in transition-metal (TM) nitrides (and, recently, TM diborides). The field of nitride hard-coatings was already developing rapidly, but reported properties varied by up to orders of magnitude. Thus, Joe and collaborators initiated systematic studies of fundamental properties of single-crystal compounds and alloys of group IIIB, IVB, VB, and VIB TM nitrides using tunable magnetically-unbalanced magnetron sputtering, which permitted independent control of ion flux and ion energy during sputter deposition. The group conducted the first systematic study of the effects of ion/metal flux ratio $\mathrm{J}_{\mathrm{i}} / \mathrm{J}_{\mathrm{Me}}$ and ion energy $E_{i}$ on microstructure evolution in hard coatings, employing a combination of surface analysis techniques, high-resolution cross-sectional transmission electron microscopy (XTEM), and electron and $\mathrm{x}$-ray diffraction. They demonstrated that ion bombardment regimes in which $\mathrm{E}_{\mathrm{i}}$ is maintained constant at values less than lattice-atom displacement energies, with high $\mathrm{J}_{\mathrm{i}} / \mathrm{J}_{\mathrm{Me}}$ values (up to $>50$ ), provide the ability to controllably manipulate film nanostructure during lowtemperature growth of polycrystalline transition metal nitride films. He also used high $\mathrm{J}_{\mathrm{i}} / \mathrm{J}_{\mathrm{Me}}$ flux ratios with low-energy ions to carry out low-temperature epitaxy of a wide range of TM nitride compounds, alloys, and metastable phases in order to determine their fundamental physical 
properties. Examples include the first (001)-oriented epitaxial $\mathrm{CrN}, \mathrm{ScN}, \mathrm{TaN}, \mathrm{CeN}, \mathrm{YN}, \mathrm{HfN}$, $\mathrm{VN}, \mathrm{ZrN}$ compounds, and their alloys, as well as epitaxial metastable cubic $\operatorname{Ti}_{1-\mathrm{x}} \mathrm{Al}_{\mathrm{x}} \mathrm{N}, \mathrm{Ti}_{1-\mathrm{x}} \mathrm{W}_{\mathrm{x}} \mathrm{N}$, $\mathrm{Sc}_{1-\mathrm{x}} \mathrm{Ti}_{\mathrm{x}} \mathrm{N}$, and $\mathrm{Hf}_{1-\mathrm{x}} \mathrm{Al}_{\mathrm{x}} \mathrm{N}$. His determinations of the properties of this class of materials are referred to as reference standards in the field. To provide just two examples: he determined the band structure and opto-electronic properties of semiconducting $\mathrm{ScN}$ and $\mathrm{ScTiN}$ alloys and was the first to demonstrate vacancy hardening (and, recently, toughening) effects, through measurements of fundamental elastic constants as a function of vacancy concentration, in understoichiometric transition metal nitrides.

Professor Greene also demonstrated enhanced hardness in superlattices with alternate layers chosen to have large differences in shear moduli, strong electron/phonon interactions, enhanced ductility using alloy design via electronic structure, and self-organized nanostructures. With polycrystalline TM nitrides, Joe and colleagues recently developed a strategy for the growth of fully-dense/low-stress/high-hardness ceramic alloys, with no substrate heating, based upon a novel hybrid dc-magnetron/high-power impulse magnetron sputtering (HiPIMS) approach. In the field of boron-containing coating they were the first to demonstrate controlled B/TM ratios in diboride layers using: (i) strong external magnetic fields during magnetron sputtering, and (ii) controlling pulse lengths, at constant power and frequency, during HiPIMS. His urge to combine computations and simulations with experimental studies, most noteworthy classical and ab-initio molecular dynamics simulations of the growth of TiN with different crystallographic orientations has led to a detailed atomic-scale understanding of the growth of these materials.

Joe also has outstanding accomplishments as a teacher and mentor. He has supervised over $70 \mathrm{PhD}$ students mainly at the University of Illinois, but also at Linkoping University and National Taiwan University of Science and Technology where he holds professorships. He has hosted over a 100 visiting scientists and post-doctoral researchers. Joe received the 1998 Aristotle Mentor Award from Semiconductor Research Consortium and the Society of Vacuum Coaters Mentor Award (2015). Joe teaches several short courses on thin films, physics, surface and nanoscience, which have been attended by thousands of students around the globe from industry and academia. Joe's students have won over 40 major society awards from the American Vacuum Society (AVS), the International Conference of Metallurgical Coatings and Thin Films (ICMCTF), the Materials Research Society (MRS), and American Physical Society (APS). Joe has been generously 
supporting the careers of his students and collaborators with valuable advice, recommendation letters, and award nominations. There is a whole cohort of scientists who have come out of Joe's school who are now leaders in their own right in academia and industry.

Joe has received numerous awards, including the major awards of APS, MRS, AVS, and SVC. He is Fellow of AVS, APS, and MRS and is an elected Member of the US National Academy of Engineering and the European Academy of Sciences. He received the Tage Erlander Award from the Swedish Natural Science Research Council. In addition, Professor Greene received a lifetime achievement award from the Taiwan Association for Coating and Thin Film Technology (TACT) for his decisive contribution in making the TACT conference a world-class event. Joe's passion for history led him, in recent years, to publish a series of scholarly articles on the recorded history of sputter deposition, organic thin films, and inorganic thin films, which was acknowledged by his receiving the 2016 George Sarton Award and Lecture, presented by the History of Science Society for lifetime scholarly achievement. Joe was also named the 2016 George Sarton Chair for the History of Science at Ghent University, Ghent, Belgium.

He is currently Editor-in-Chief of Thin Solid Films and past Editor of CRC Critical Reviews in Solid State and Materials Sciences. Joe is an unsurpassed writer with a style that is characterized by logic, conciseness, and elegance. As a Director of Frederick Seitz Materials Research Laboratory at the University of Illinois, he elevated the research program to new heights, including building its Center for Microanalysis of Materials as a prominent National User Facility.

Joe's contribution to societies and his service to the scientific community are legendary. His visionary leadership activity in the AVS, for which he is a Past-President, has contributed significantly to making it the internationally society in the field of vacuum-based science and technology. Today, he is still the AVS Secretary and is a highly sought-after advisor on all relevant developments. He has served for decades in leading roles in the Advanced Surface Engineering Division (ASED) of the AVS and its major conference ICMCTF. He has helped develop ICMCTF to the premier international event in the field. His impact on this annual meeting and his ability to educate attendees in the spirit of cooperation and friendship have made ICMCTF and San Diego the home of generations of colleagues from academia, governmental institutions, and industry. In 2019, the ICMCTF community awarded him the Bunshah Award of the highest ASED recognition for his lifetime achievements. 
In his "spare" time, Joe is an avid mountaineer and volunteer Search and Rescue Ranger at the Grand Teton National Park.

Joe continues to pursue science and we, the Guest Editors, wish him a continuously stimulating future and otium cum dignitate.

\author{
Professor Ivan Petrov, \\ Frederick Seitz Materials Research Lab \\ University Illinois of at Urbana-Champaign, USA \\ and \\ Department of Physics, IFM \\ Linköping University, Sweden \\ email: petrov@illinois.edu \\ Professor Dr. Lars Hultman \\ Department of Physics, IFM \\ Linköping University, Sweden \\ email:1arhu@ifm.liu.se \\ Dr.-Ing. Michael Stueber, \\ Karlsruhe Institute of Technology (KIT) \\ Eggenstein-Leopoldshafen, Germany \\ email: michael.stueber@kit.edu \\ Professor Li-Chyong Chen \\ Center for Condensed Matter Sciences \\ National Taiwan University, Taiwan \\ email: chenlc@ntu.edu.tw \\ Professor Patrick Desjardins \\ Department of Engineering Physics \\ École Polytechnique de Montreal, Canada \\ email: patrick.desjardins@polymtl.ca
}

